\title{
Effects of positive and negative stretching on the structure and properties of polyacrylonitrile fibers in the pre-oxidation process
}

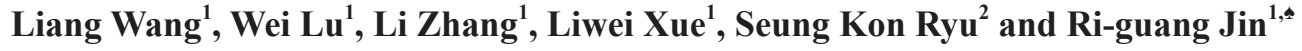 \\ ${ }^{1}$ State Key Laboratory of Chemical Resource Engineering, Beijing University of Chemical Technology, Beijing 10029, China \\ ${ }^{2}$ Department of Chemical Engineering, Chungnam National University, Daejeon 305-746, Korea
}

\section{Article Info \\ Received 15 February 2011 \\ Accepted 23 May 2011 \\ *Corresponding Author \\ E-mail: jin.riguang@163.com}

\section{Open Access}

DOI: 10.5714/CL.2011.12.2.107

This is an Open Access article distributed under the terms of the Creative Commons Attribution Non-Commercial License (http://creativecommons.org/licenses/ by-nc/3.0/) which permits unrestricted non-commercial use, distribution, and reproduction in any medium, provided the original work is properly cited.

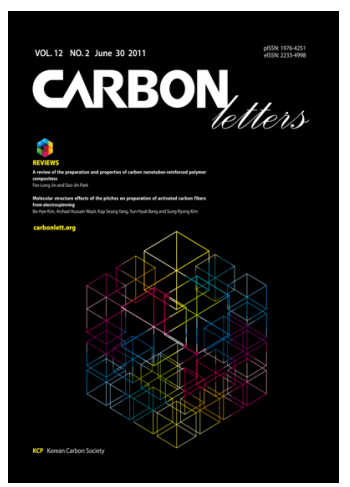

http://carbonlett.org

pISSN: 1976-4251

elSSN: 2233-4998

Copyright $\odot$ Korean Carbon Society

\begin{abstract}
Polyacrylonitrile (PAN) fibers were pre-oxidized in a temperature range of $180-275^{\circ} \mathrm{C}$. The effects of positive and negative stretching on the structure and morphology of PAN fiber in the pre-oxidation process were studied by FTIR spectroscopy, XRD, and SEM. Mechanical property changes were also investigated. No changes in the movement and intensity of functional groups of PAN fibers were caused by positive stretching of up to $10 \%$ and negative stretching down to $-8 \%$. The crystal structure can be affected by the positive stretching and negative stretching. The maximum strength is $479.81 \mathrm{MPa}$ when the stretching is positive, and the maximum strength is $420.55 \mathrm{MPa}$ when the stretching is negative.
\end{abstract}

Key words: polyacrylonitrile, positive stretching, negative stretching, pre-oxidation

\section{Introduction}

It has been well established that polyacrylonitrile (PAN) fibers are one of the most suitable and widely used precursors for making high-performance carbon fiber, and PAN-based carbon fiber is stronger than other types precursor-based carbon fibers [1]. Developing carbon fiber from PAN based fiber generally involves three processes, namely stabilization, carbonization, and graphitization under controlled conditions. Among those processes, pre-oxidation is a very important step because it largely governs the final structure and mechanical properties of the carbon fiber. During this process in a temperature range of $180-280^{\circ} \mathrm{C}$, PAN precursors are converted into infusible and nonflammable fibers with a ladder structure suitable for further carbonization [2]. Important factors such as temperature, time, and stretching have been studied previously [3-9]; however, systematic investigations of the effects of positive and negative stretching have never been reported relating to the structure and properties of PAN fibers in the pre-oxidation process.

In this work, the effects of positive and negative stretching on the structure and properties of PAN fibers in the pre-oxidation process were systematically investigated by using FTIR spectroscopy, XRD, and SEM observations.

\section{Experimental}

\subsection{Materials}

The PAN fiber used in this experiment was supplied by Zhongfu Shenying Carbon Fiber Co., Ltd. (Lianyungang, People's Republic of China) in tows of 1,000 fibers with an average density of $1.19 \mathrm{~g} / \mathrm{cm}^{3}$ and a mean diameter of $12.4 \mu \mathrm{m}$. 


\subsection{Pre-oxidation of PAN fibers}

Pre-oxidation was carried out in a furnace divided into nine temperature zones in a range of $180-300^{\circ} \mathrm{C}$. Temperature gradually increased so as to control pre-oxidation temperature gradient. The stretching ratio was achieved by controlling the speed difference between the feed $\left(\mathrm{v}_{1}\right)$ and take-up rollers $\left(\mathrm{v}_{2}\right)$. The stretching ratio is determined by the follow equation: $\tau=\left[\left(\mathrm{v}_{2}-\mathrm{v}_{1}\right) / \mathrm{v}_{1}\right] \times 100 \%$, where if $\tau=0$, it means no stretching, if $\tau>0$, it means positive stretching, and if $\tau<0$, it means negative stretching.

Table 1 shows various stretching ratios during the increase of the pre-oxidation temperature. $\tau_{1}$ means stretching ratio was $2 \%$ at $180^{\circ} \mathrm{C}$, and it was increased $2 \%$ at $200^{\circ} \mathrm{C}$ and then constantly sustained until $275^{\circ} \mathrm{C}$. Therefore, the total positive stretching ratio was $4 \%$. On the other hand, in the case of $\tau_{5}$, the fiber was relaxed $2 \%$ by supplying negative stretching at $270^{\circ} \mathrm{C}$. Therefore, the total stretching ratio was also $4 \%$; however, $\tau_{5}$ contained negative stretching.

\section{Table 1. Parameters of pre-oxidation process}

\begin{tabular}{cccccc} 
Total & \multicolumn{5}{c}{ Temperature $\left({ }^{\circ} \mathbf{C}\right)$} \\
\cline { 2 - 6 } $\begin{array}{c}\text { stretching } \\
\text { ratio (\%) }\end{array}$ & $\mathbf{1 8 0}$ & $\mathbf{2 0 0}$ & $\mathbf{2 2 0 - 2 6 5}$ & $\mathbf{2 7 0}$ & $\mathbf{2 7 5}$ \\
\hline$\tau_{1}$ & 2 & 2 & 0 & 0 & 0 \\
$\tau_{2}$ & 4 & 2 & 0 & 0 & 0 \\
$\tau_{3}$ & 6 & 2 & 0 & 0 & 0 \\
$\tau_{4}$ & 8 & 2 & 0 & 0 & 0 \\
$\tau_{5}$ & 4 & 2 & 0 & 0 & -2 \\
$\tau_{6}$ & 4 & 2 & 0 & 0 & -4 \\
$\tau_{7}$ & 4 & 2 & 0 & 0 & -6 \\
$\tau_{8}$ & 4 & 2 & 0 & 0 & -8 \\
\hline
\end{tabular}

\subsection{IR spectroscopy}

IR spectroscopy was performed to observe the effects of the pre-oxidation conditions. FTIR measurements were conducted through the loading of samples on $\mathrm{KBr}$ disks $(0.5 \mathrm{mg}$ sample mixed with $200 \mathrm{mg}$ of $\mathrm{KBr}$ ). The sample fibers were obtained from the production line after undergoing different treatments on a Nicolet-210 FTIR spectrometer with a resolution of $4 \mathrm{~cm}^{-1}$. The cyclization rate (we prefer the cyclization, not the relative cyclization rate) $(\eta)$ is defined in terms of the intensities of the spectrocsopy peaks [10]:

$$
\eta=\left[I_{C=N} /\left(I_{C \equiv N}+I_{C=N}\right)\right] \times 100 \%
$$

where $I_{C=N}$ is the measured intensity of the conjugated band at $1630 \mathrm{~cm}^{-1}$ associated with the developing structure and $I_{C \equiv N}$ is the measured intensity of the nitrile band at $2240 \mathrm{~cm}^{-1}$ belonging to the unmodified PAN molecule.

\subsection{Wide-angle XRD}

A Rigaku X-ray powder diffractometer (Rigaku Co., Tokyo, Japan) was used to study the wide-angle XRD (WAXRD) pattern with $\mathrm{CuK}_{\alpha}$ radiation (wave length $\lambda=1.54 \AA$ ) as a source. The step interval was $0.02^{\circ}$. The interplaner spacing (d-space) is determined by the Bragg equation:

$$
\lambda=2 \mathrm{~d} \sin \theta
$$

where $\lambda$ is the wavelength of the X-rays.

The aromatization index (AI) was determined by the following equation:

$$
\mathrm{AI}=I_{a} /\left(I_{a}+I_{p}\right)
$$

where $I_{a}$ is the intensity of diffraction at $2 \theta=25.5^{\circ}$, which is given by the ladder structure and $I_{p}$ is the intensity of diffraction at $2 \theta=17^{\circ}$.

\subsection{Mechanical properties}

The mechanical properties of the PAN pre-oxidized fibers were measured with a single fiber strength machine (YG004E, Ningbo Textile Machinery Co., China). In each case, at least 40 samples were tested. Discarding the top 5 and bottom 5 , the average value of the remaining 30 can be automatically obtained. The diameter of each fiber was measured with a (Olympus) microscope before the tensile test.

\subsection{Scanning electron microscope}

The fractured surface of PAN pre-oxidized fibers were observed by using a field emission-SEM (Hitachi S-4700, Japan) with a revolution of $15 \mathrm{kV}$. Before observation, the samples were embedded in an epoxy resin and sputter-coated using $\mathrm{Pt}$ (JEOL JFC-1200, USA).

\section{Results and Discussion}

\subsection{Positive stretching on the structure and properties}

Fig. 1 shows the FTIR spectroscopy of the pre-oxidized PAN fibers at different positive stretching ratios. The positive stretching ratio did not show any influence on the movement and intensity of the functional groups until $10 \%$. There were weak absorption bands at $2243 \mathrm{~cm}^{-1}$ assigned to the nitrile group and, at $1581 \mathrm{~cm}^{-1}$, were assigned to the vibration of carboxyl groups, which indicated that oxidation has occurred. The cyclization rate was calculated according to Eq. (1) based on Fig. 1 and is listed in Table 2.

Fig. 1 shows there is no obvious influence on the movement and intensity of functional groups of FTIR, and the cyclization rate is also affected less, which indicates that positive stretching cannot affect the chemical structure.

Fig. 2 shows the WAXRD patterns of pre-oxidized PAN fibers at different positive stretching ratios. The spectra of pre-oxidized PAN fibers shows a weak diffraction at $2 \theta=17^{\circ}$ and a broad diffraction at $2 \theta=25.5^{\circ}$. According to Eqs. (2) and (3), structural parameters were calculated and listed in Table 3. The d-spacing of diffraction at $17^{\circ}$ was $5.29 \AA$, obtained from a stretching ratio of $6 \%$. However, the $\mathrm{d}$-space diffraction around $25.5^{\circ}$ shows an increased trend. The AI 


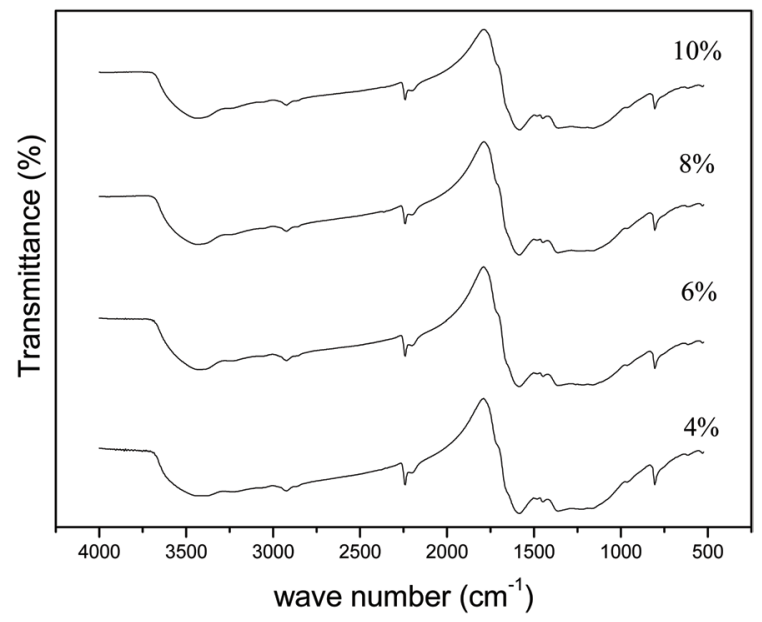

Fig. 1. Fourier transform infrared spectroscopy of pre-oxidized polyacrylonitrile fibers at different positive stretching ratios.

Table 2. Cyclization rate based on the FTIR spectroscopy in Fig. 1

\begin{tabular}{ccccc} 
Stretching ratio (\%) & $\mathbf{4}$ & $\mathbf{6}$ & $\mathbf{8}$ & $\mathbf{1 0}$ \\
\hline$\eta(\%)$ & 58.97 & 60.72 & 59.87 & 57.69 \\
\hline
\end{tabular}

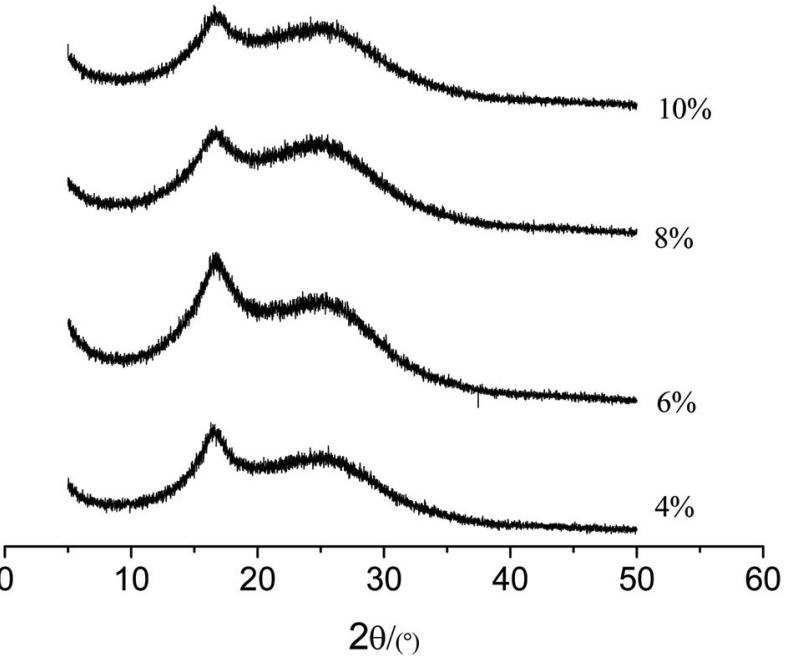

Fig. 2. X-ray diffraction patterns of the pre-oxidized polyacrylonitrile fibers at different positive stretching ratios.

values increased with an increase in the stretching ratio, indicating that stretching promoted the reactions. In fact, stretching affected the readjustment of the molecular chains (involving the rotation of nitrile groups around the $\mathrm{C}-\mathrm{C}$ single bond) not only in the ordered domains but also and especially in the disordered domains. This might have brought more nitrile groups into a suitable position for cyclization. So, one can conclude that stretching offers molecular chains additional energy to readjust and pack into an ordered phase, which is accordant to the results of Wu et al [5]. It was also found that stretching had a significant influence on the physical structure of PAN fibers [3].

Although the tension evolution during the pre-oxidation of PAN fibers has been investigated [4], the mechanical properties of pre-oxidized PAN fibers should also be tested, and they were

\begin{tabular}{|c|c|c|c|c|c|}
\hline Stretching ratio (\%) & $2 \theta\left({ }^{\circ}\right)$ & D ( $(\AA)$ & $2 \theta\left(\left(^{\circ}\right)\right.$ & D (Å) & AI (\%) \\
\hline 4 & 16.30 & 5.43 & 25.61 & 3.47 & 43.19 \\
\hline 6 & 16.73 & 5.29 & 25.49 & 3.49 & 42.12 \\
\hline 8 & 16.69 & 5.31 & 25.55 & 3.48 & 46.01 \\
\hline 10 & 16.55 & 5.35 & 25.27 & 3.52 & 46.68 \\
\hline
\end{tabular}

Al: aromatization index.

Table 4. Mechanical properties of pre-oxidized PAN fibers at different positive stretching ratios

\begin{tabular}{ccccc}
$\begin{array}{c}\text { Stretching } \\
\text { ratio (\%) }\end{array}$ & $\begin{array}{c}\text { H } \\
\mathbf{( \% )}\end{array}$ & $\begin{array}{c}\text { Tensile } \\
\text { strength } \\
\text { (MPa) }\end{array}$ & $\begin{array}{c}\text { Elongation to } \\
\text { break (\%) }\end{array}$ & $\begin{array}{c}\text { Tensile } \\
\text { power }\end{array}$ \\
\hline 4 & 59.76 & 498.71 & 12.1 & 6034.34 \\
6 & 60.73 & 333.35 & 12.0 & 4000.18 \\
8 & 59.87 & 342.17 & 11.1 & 3798.09 \\
10 & 57.69 & 271.93 & 11.7 & 3181.63 \\
\hline
\end{tabular}

PAN: polyacrylonitrile.

listed in Table 4 in increasing order of the positive stretching ratio. The tensile strength and tensile power of the

PAN fibers for the $4 \%$ stretching ratio were higher than those of the other three samples and had a decreasing trend. However, there was no obvious difference among the elongation to break. Tensile power stands for the work involved in breaking the fibers and could be defined in terms of the product of strength and tensile power. Fig. 3 shows the SEM images of pre-oxidized PAN fibers at different positive stretching ratios. When the stretching ratio is at $4 \%$ (Fig. 3a), the fractured surface radiates from the center to the surrounding is and distributes equally, indicating that the internal binding force of fibers are large and the tensile strength and tensile power are larger. When the stretching ratio was at $6 \%$ (Fig. 3b), the toughness decreased and the fractured surface became smooth, resulting in a dramatically drop in tensile strength and tensile power. When the stretching ratio was at $8 \%$ (Fig. $3 \mathrm{c}$ ), the fractured surface of pre-oxidized PAN fibers became rough, and the tensile strength increased a little. When the stretching ratio was at $10 \%$, it prevented penetration into the PAN molecule and broke the molecular order and orientation so that the pre-oxidation was insufficient with large radial differences, resulting in uneven molecular structure and decreased tensile strength. As shown in Fig. 3d, the fractured surface is quite rough, implying that the internal stress was not equal and bonding force decreased, and then the tensile strength and tensile power decreased. In a word, the tensile strength and tensile power have the same performance. It is necessary to consider the tensile strength and tensile power to obtain both the elongation and strength so that it performs well when it is used; meanwhile, the stretching ratio should not be too large so as to avoid performance degradation [11]. Except for the results above, the evolution of structure and the changes of properties during the pre-oxidation on other important aspects have been studied by Zhang et al [7]. 

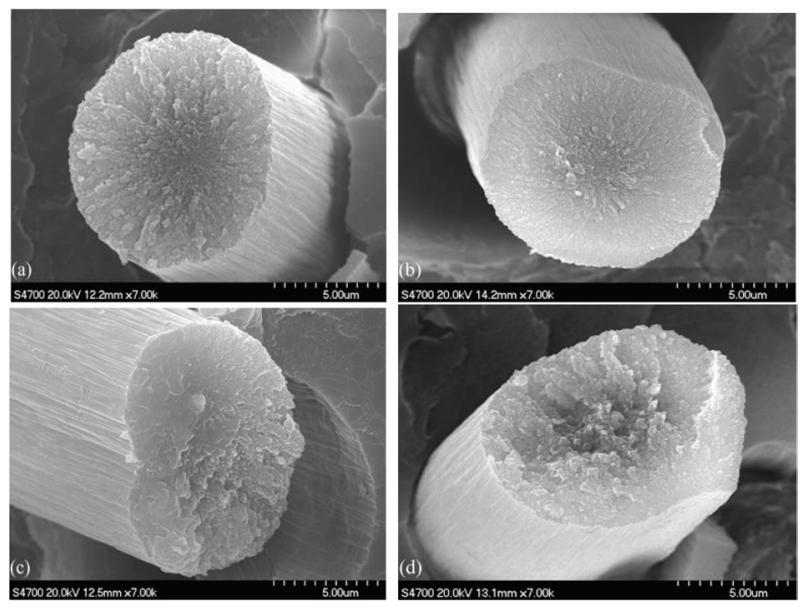

Fig. 3. Scanning electron microscope images of pre-oxidized polyacrylonitrile fibers at different positive stretching ratios: (a) 4, (b) 6, (c) 8, and (d) $10 \%$.

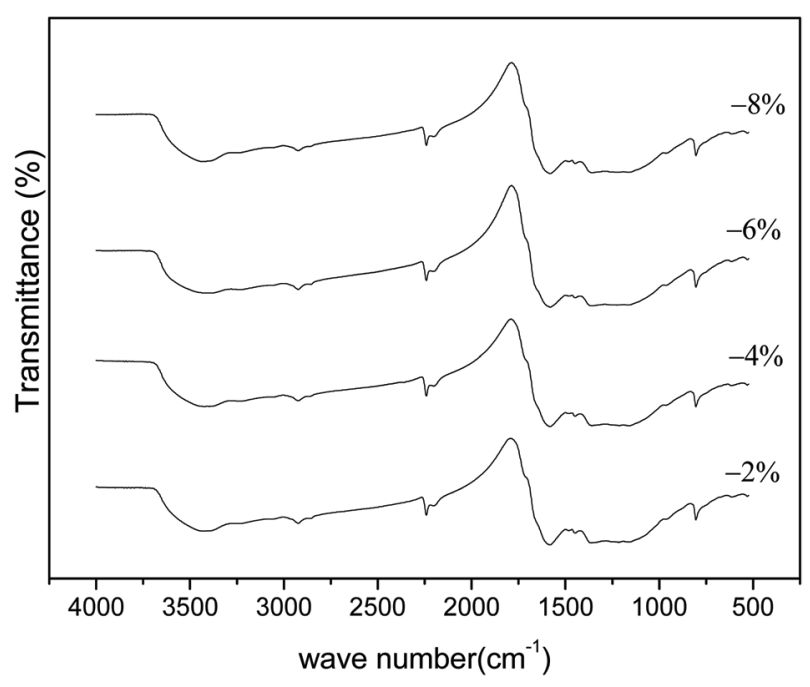

Fig. 4. Fourier transform infrared spectroscopy of pre-oxidative polyacrylonitrile fibers at different negative stretching ratios.

\subsection{Negative stretching on the structure and properties}

Wang et al [3] has investigated the structure and properties of PAN fibers from the negative stretching in the high temperature zone. Fig. 4 shows the FTIR spectroscopy of the pre-oxidized PAN fibers at different negative stretching ratios. As with positive stretching, the FTIR spectra showed that negative stretching still has no influence on the movement and intensity of functional groups. The cyclization rate has been calculated according to Eq. (1) based on Fig. 4 and is listed in Table 5. The effect of the cyclization rate by negative stretching is not obvious, just as with positive stretching.

Fig. 5 shows WAXRD patterns of pre-oxidized PAN fibers at different negative stretching ratios. In general, the spectra of pre-oxidized PAN fibers showed weak diffraction at $2 \theta=17^{\circ}$ and a broad diffraction around $2 \theta=25.5^{\circ}$. There are no obvious differences the ratios decrease.
Table 5. Relative cyclization rate based on FIR spectroscopy in Fig. 4

\begin{tabular}{ccccc} 
Stretching ratio (\%) & $\mathbf{- 2}$ & $\mathbf{- 4}$ & $\mathbf{- 6}$ & $\mathbf{- 8}$ \\
\hline$\eta(\%)$ & 58.20 & 58.75 & 61.55 & 59.58 \\
\hline
\end{tabular}

FTIR: Fourier transform infrared spectroscopy.

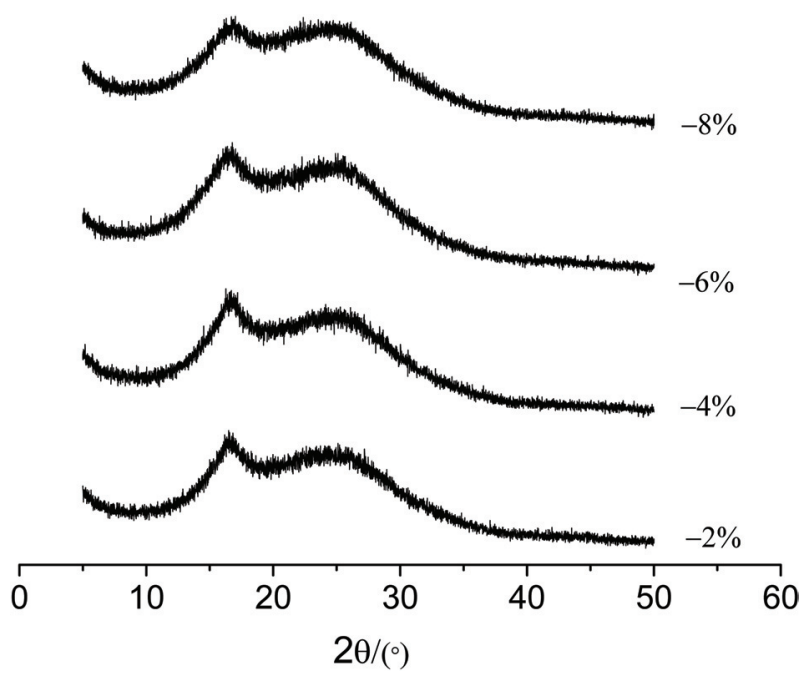

Fig. 5. Wide-angle X-ray diffraction patterns of pre-oxidized polyacrylonitrile fibers at different negative stretching ratios.

\begin{tabular}{|c|c|c|c|c|c|}
\hline $\begin{array}{c}\text { Stretching } \\
\text { ratio (\%) }\end{array}$ & $2 \theta\left({ }^{\circ}\right)$ & d $(\AA)$ & $2 \theta\left({ }^{\circ}\right)$ & d $(\AA)$ & AI (\%) \\
\hline-2 & 16.5 & 5.37 & 25.1 & 3.54 & 45.43 \\
\hline-4 & 16.27 & 5.44 & 25.29 & 3.52 & 47.65 \\
\hline-6 & 16.79 & 5.27 & 24.91 & 3.57 & 47.32 \\
\hline-8 & 17.02 & 5.20 & 24.73 & 3.60 & 47.87 \\
\hline
\end{tabular}

Al: aromatization index.

Structural parameters were calculated according to Eqs. (2) and (3) and were listed in Table 6 . When the stretching ratio was $-4 \%$, the d-spacing diffraction at $17^{\circ}$ and around $25.5^{\circ}$ were the higher and lower than the other three samples, respectively; however, the AI values increased with an increase in the negative stretching ratio.

Table 7 shows that relative cyclization rate was the highest but not the tensile strength, indicating that the oxygen entered the PAN molecule chain easily but may have caused an overreaction, resulting in the decreased tensile strength. When the stretching ratio was $-4 \%$, the tensile strength of the pre-oxidized PAN fibers was higher than the other three groups, but the elongation at break was lower than the other three groups, of which the elongations to break of the three groups were nearly the same; nevertheless, the tensile power of the former three groups was nearly the same but higher than that of the stretching ratio $-8 \%$. Meanwhile, as shown in Tables 4 and Table 7, the elongation to break the pre-oxidized PAN fibers after the negative stretching was higher than that of the positive stretching. When the stretching was $-2 \%$, because of the drastic 
Table 7. Mechanical properties of pre-oxidized PAN d fibers at different negative stretching ratios

\begin{tabular}{ccccc}
$\begin{array}{c}\text { Stretching } \\
\text { ratio (\%) }\end{array}$ & $\begin{array}{c}\text { H } \\
(\%)\end{array}$ & $\begin{array}{c}\text { Tensile } \\
\text { strength } \\
\text { (MPa) }\end{array}$ & $\begin{array}{c}\text { Elongation } \\
\text { to break (\%) }\end{array}$ & $\begin{array}{c}\text { Tensile } \\
\text { power }\end{array}$ \\
\hline-2 & 58.20 & 378.11 & 13.2 & 4991.04 \\
-4 & 58.75 & 420.55 & 11.9 & 5004.52 \\
-6 & 61.54 & 366.56 & 13.1 & 4801.98 \\
-8 & 59.58 & 288.23 & 13.1 & 3775.76 \\
\hline
\end{tabular}

PAN: polyacrylonitrile.
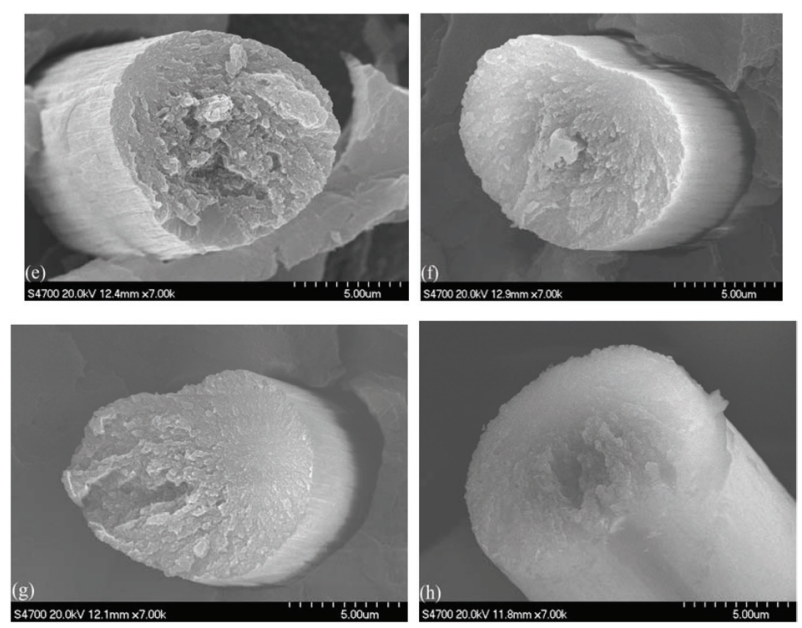

Fig. 6. Scanning electron microscope images of pre-oxidized polyacrylonitrile fibers at different negative stretching ratios: (e) -2 , (f) -4, (g) -6 , and (h) $-8 \%$.

oxidation, it was difficult for oxygen to enter the PAN molecule, and this resistance caused the oxidation to not occur easily, resulting in the uneven structure of the pre-oxidized PAN fibers. Fig. 6 shows SEM images of pre-oxidized PAN fibers at different negative stretching ratios. When the stretching ratio was $-2 \%$ (Fig. 6e), the fractured surface showed an uneven stress of internal molecules and could not spread after the tensile force; therefore, the tensile strength was not very high. When the stretching ratio was $-4 \%$, this was helpful for oxygen to penetrate into PAN molecular chains to oxidize and form an equal structure of pre-oxidized PAN fibers. The SEM image (Fig. 6f) also showed a better fractured surface than the other three groups of samples. As the stretching ratio was increased to $-6 \%$, oxygen molecules could penetrate into PAN molecular chains to peroxide and result in a decrease in tensile strength, but the elongation to break increased. When the stretching ratio was $-6 \%$ (Fig. $6 \mathrm{~g}$ ), the fractured surface was rougher than that of pre-oxidized PAN fibers at a stretching ratio of $-4 \%$, and some obvious crack can be also seen clearly. When the stretching ratio increased to $-8 \%$, excessive oxygen molecule penetrated into the internal PAN molecular chains, but it was too late to deoxygenate and dehydrogenate before the oxidation was completed. As shown in Fig. 6h, it is hard to see the obvious fractured surface, indicating that the oxidation was rather excessive. Meanwhile, excessive negative stretching made the fibers too relaxed, resulting in irregular internal distribution of the PAN molecular chain, leading to low tensile strength and tensile power. Consequently, when the negative stretching ratio was in the range between -2 and $-4 \%$, the properties of PAN fibers performed well.

\section{Conclusions}

PAN fibers were pre-oxidized at different stretching ratios in the range of $180-275^{\circ} \mathrm{C}$. The tensile strength of pre-oxidized PAN fibers decreased gradually with an increase in the positive stretching ratio. There is no obvious influence on the chemical structure, whether the stretching is positive and negative; however, the crystal structure was affected by them, and the positive stretching affected the readjustment of the molecular chains and might have brought more nitrile groups into a suitable position for cyclization. The maximum strength is $479.81 \mathrm{MPa}$ when the stretching is positive and the maximum strength is 420.55 MPa when the stretching is negative.

\section{References}

[1] Cato AD, Edie DD. Flow behavior of mesophase pitch. Carbon, 41, 1411 (2003). doi: 10.1016/s0008-6223(03)00050-2.

[2] Rahaman MSA, Ismail AF, Mustafa A. A review of heat treatment on polyacrylonitrile fiber. Polym Degradation Stab, 92, 1421 (2007). doi: 10.1016/j.polymdegradstab.2007.03.023.

[3] Wang PH. Aspects on prestretching of PAN precursor: Shrinkage and thermal behavior. J Appl Polym Sci, 67, 1185 (1998). doi: 10.1002/ (sici)1097-4628(19980214)67:7<1185::aid-app3>3.0.co;2-c.

[4] Yu M, Wang C, Bai Y, Wang Y, Zhu B. Evolution of tension during the thermal stabilization of polyacrylonitrile fibers under different parameters. J Appl Polym Sci, 102, 5500 (2006). doi: 10.1002/ app. 23960 .

[5] Wu G, Lu C, Ling L, Hao A, He F. Influence of tension on the oxidative stabilization process of polyacrylonitrile fibers. J Appl Polym Sci, 96, 1029 (2005). doi: 10.1002/app.21388.

[6] Dalton S, Heatley F, Budd PM. Thermal stabilization of polyacrylonitrile fibres. Polymer, 40, 5531 (1999). doi: 10.1016/s00323861(98)00778-2.

[7] Wangxi Z, Jie L, Gang W. Evolution of structure and properties of PAN precursors during their conversion to carbon fibers. Carbon, 41, 2805 (2003). doi: 10.1016/s0008-6223(03)00391-9.

[8] Yu M, Wang C, Bai Y, Zhu B, Ji M, Xu Y. Microstructural evolution in polyacrylonitrile fibers during oxidative stabilization. J Polym Sci, Part B: Polym Phys, 46, 759 (2008). doi: 10.1002/ polb. 21410 .

[9] Hou Y, Sun T, Wang H, Wu D. Thermal-shrinkage investigation of the chemical reaction during the stabilization of polyacrylonitrile fibers. J Appl Polym Sci, 114, 3668 (2009). doi: 10.1002/ app.30303.

[10] Bhat GS, Cook FL, Abhiraman AS, Peebles Jr LH. New aspects in the stabilization of acrylic fibers for carbon fibers. Carbon, 28, 377 (1990). doi: 10.1016/0008-6223(90)90011-m.

[11] Ozbek S, Isaac DH. Strain-induced density changes in PAN-based carbon fibres. Carbon, 38, 2007 (2000). doi: 10.1016/s00086223(00)00060-9. 